\title{
The effect of cadmium on brain cells in culture
}

\author{
CHRISTIAN GERSPACHER $^{1 *}$, URS SCHEUBER ${ }^{1 *}$, GABRIELLA SCHIERA $^{2}$, \\ PATRIZIA PROIA ${ }^{3}$, DANIEL GYGAX ${ }^{4}$ and ITALIA DI LIEGRO ${ }^{2}$ \\ ${ }^{1}$ Dipartimento di Biologia Cellulare e dello Sviluppo, ${ }^{2}$ Dipartimento di Scienze Biochimiche, and \\ ${ }^{3}$ Dipartimento di Studi Giuridici, Economici, Biomedici, Psicosociopedagogici delle \\ Scienze Motorie e Sportive, Università degli Studi di Palermo, Palermo, Italy; \\ ${ }^{4}$ University of Applied Sciences Northwestern Switzerland, Muttenz, Switzerland
}

Received March 17, 2009; Accepted April 27, 2009

DOI: $10.3892 /$ ijmm_00000234

\begin{abstract}
Cadmium is a long-living heavy metal, abundantly present in the environment, which accumulates in the body. In this study, we investigated the effects of cadmium on the expression of molecular chaperones, and of certain cell-specific proteins, in a variety of brain cell types in culture, namely primary cultures of rat cortical neurons and astrocytes, a brain capillary endothelial cell line (RB4E.B cells), and pheochromocytoma cells (PC12), induced or not to differentiate by NGF treatment. The metal induces a dose-dependent increase of Hsp70 in all cell types. Responses to the metal are cellspecific in the case of Hsc70 and Hsp90: i) in astrocytes, as well as in PC12 cells, cadmium has no significant effect; ii) in endothelial cells, an increase of both proteins is clearly observable from $20 \mu \mathrm{M}$ cadmium; iii) both Hsp90 and Hsc70 decrease in neurons treated with high doses of cadmium. Damage to the cytoskeleton in treated cells was also evident. Finally, we report that the metal at high doses induces a decrease of PIPPin (also known as CSD-C2), a putative RNAbinding protein highly expressed in neurons and probably involved in the regulation of histone replacement variant expression.
\end{abstract}

\section{Introduction}

Because of its high environmental impact and its long biological half-life of $\sim 30$ years, cadmium is a heavy metal of high potential toxicity (1). Carcinogenic effects, as well as damage of several organs (2-5), are caused by the exposure to this metal, which also alters gametogenesis and embryogenesis

Correspondence to: Professor Italia Di Liegro, Dipartimento di Scienze Biochimiche, Via del Vespro 129, 90127 Palermo, Italy E-mail: diliegro@unipa.it

${ }^{*}$ Contributed equally

Key words: cadmium, brain cells, molecular chaperones, PIPPin
$(6,7)$, interfering with normal development and/or inducing apoptotic responses in embryos (8-10). A prominent effect of cadmium is the induction of oxidative stress both in vivo and in cultured cells (11-15). As a response to cadmium-induced stress, many cells activate the synthesis of heat shock proteins (Hsps) $(10,16,17)$, in a heat shock factor (HSF)-dependent manner (17).

Cadmium enters the central nervous system either through the olfactory pathway or by altering the permeability of the blood-brain barrier (18-21), and has been reported to cause lipid peroxidation (15), damage to DNA (22), and alteration of calcium homeostasis (23-25). Cadmium was also demonstrated to affect metabolism, release and re-uptake of different neurotransmitters (26-29). Although the complexity of the cellular and biochemical actions of cadmium have been discussed in a number of studies, the underlying mechanisms are not completely understood. In particular, it is not clear whether all the different populations of brain cells (i.e. neurons, glial cells, and endothelial cells) are equally sensitive to the metal, and whether they activate cell responses to cadmium that involve similar pathways.

In this study, we directly compared the effects of the metal on different kinds of brain cells, using as reference the expression of three molecular chaperones (Hsp70, Hsc70, and Hsp90), as well as the expression and sub-cellular localization of certain cell-specific proteins, such as the nerve cell-specific microtubule-associated protein MAP-2 and the astrocyte intermediate filament-specific glial fibrillary acidic protein (GFAP). We also investigated the effect of cadmium on the expression of PIPPin (also called CSD-C2), a putative RNAbinding protein discovered years ago in our laboratory (30). This protein, that contains a cold shock domain (31), is expressed in specific nerve cell populations of the brain (32), and seems to be involved in the post-transcriptional regulation of genes encoding replacement histones, such as the linker histone $\mathrm{H}^{\circ}$ and the core histone $\mathrm{H} 3.3$ (31). PIPPin is also able to interact strongly with chromatin (33). Although the function of PIPPin is not yet clear, it seems able to shuttle between the nucleus and the cytoplasm, as well as to undergo post-translational modifications, such as phosphorylation (34, and our unpublished observations) and sumoylation (33), in response to extracellular stimuli. 


\section{Materials and methods}

Animals. Sprague-Dawley rats (Stefano Morini, San Polo d'Enza, Italy) were housed in the institutional animal care facility of the Department of 'Biologia Cellulare e dello Sviluppo' (University of Palermo, Palermo, Italy), under direction of a licensed veterinary, who approved the protocols. Procedures involving animals were conducted according to European Community Council Directive 86/609, OJL 5358 1, December 12, 1987. The number of animals used has been minimized as well as their suffering.

Cell cultures. Neurons were purified from fetal rat cortices at the 16th day of gestation and cultured in a chemically defined medium (Maat Medium), on laminin, as already described (35). Astrocytes were prepared from two-day-old newborn rats, as previously described (36), and cultured in DME/Hams F-12 (2/1), supplemented with $10 \%$ heat-inactivated fetal calf serum (Sigma-Aldrich, MO, USA), until half confluence.

RBE4.B immortalized rat brain capillary endothelial cells (BCECs) (37) were kindly donated by F. Roux, under the permission of Neurotech SA (Orsay, France). BCECs were plated on collagen I and fed with NIH medium (SigmaAldrich).

Undifferentiated pheochromocytoma 12 cells (PC12) were cultured in RPMI-1640 medium, containing 10\% horse serum and $5 \%$ fetal bovine serum (Sigma-Aldrich). Before inducing differentiation, cells were plated on laminin. Nerve growth factor (NGF; Promega Corporation, WI, USA) was then added at an initial concentration of $4 \mu 1 / 2.0 \times 10^{5}$ cells. The cells were then cultured for one week more. During this time cells attached to the substratum and produced a network of neurites.

Heavy metal treatment. $\mathrm{CdCl}_{2}$ was added to the cell cultures to obtain $\mathrm{Cd}^{2+}$ final concentrations of $1,5,20$ or $50 \mu \mathrm{M}$. Treated cells as well as untreated control cells were cultured for $24 \mathrm{~h}$.

Vitality assay. Cell death was evaluated by cell staining with an acridine orange (AO)/ethidium bromide (EB) mixture, each at a concentration of $100 \mu \mathrm{g} / \mathrm{ml}$, as described (38). The staining of cells was observed by fluorescent microscopy.

Western blot analysis. After treatment, cells were collected, washed with PBS, and homogenized in homogenization buffer $(0.32 \mathrm{M}$ sucrose; $50 \mathrm{mM}$ sodium phosphate buffer, pH 6.5; $50 \mathrm{mM} \mathrm{KCl,} 0.5 \mathrm{mM}$ spermine; $0.15 \mathrm{mM}$ spermidine; $2 \mathrm{mM}$ EDTA, and $0.15 \mathrm{mM}$ EGTA), containing the protease inhibitors aprotinin $(2 \mu \mathrm{g} / \mathrm{ml})$, antipain $(2 \mu \mathrm{g} / \mathrm{ml})$, leupeptin $(2 \mu \mathrm{g} / \mathrm{ml})$, pepstatin A $(2 \mu \mathrm{g} / \mathrm{ml})$, benzamidine $(1.0 \mathrm{mM})$, and phenylmethylsulfonyl fluoride $(1.0 \mathrm{mM})$, all purchased from Sigma-Aldrich. Total protein concentration was determined by the Quant-iT ${ }^{\mathrm{TM}}$ protein assay using a Qubit ${ }^{\mathrm{TM}}$ fluorometer (Invitrogen). Equal amount of proteins (10-20 $\mu \mathrm{g}$ ) were loaded onto each lane of $12 \%$ acrylamide-SDS denaturing gels. After electrophoretic separation, samples were electroblotted onto a PVDF membrane ( $0.45 \mu \mathrm{m}$ pore-size, Amersham Biosciences). Concentrations of the samples on the membrane were visualized by staining with Ponceau red for $5 \mathrm{~min}$. Finally, the membrane was immunostained with one of the following antibodies: i) rabbit polyclonal anti-Hsp70 (Calbiochem, Darmstadt, Germany); ii) mouse polyclonal anti-Hsc70 (Santa Cruz, CA, USA); iii) mouse monoclonal anti-Hsp90 (Calbiochem); iv) mouse monoclonal anti-microtubule associated protein (MAP)-2 (Sigma-Aldrich); v) rabbit polyclonal anti-glial fibrillary acidic protein (GFAP; SigmaAldrich); vi) rabbit polyclonal anti-PIPPin antibody was obtained in our laboratory, by immunizing rabbits with recombinant PIPPin, as already described (31). The secondary, anti-rabbit or anti-mouse antibodies were from Promega Corporation.

Immunofluorescence microscopy. Neurons and differentiated PC12 were cultured on coverslips coated with laminin or polyD-lysine respectively. After treatment, cells were fixed with 96\% ethanol, on ice, for $10 \mathrm{~min}$ and permeabilized for $5 \mathrm{~min}$ with $0.1 \%$ Triton $\mathrm{X}-100$, in PBS. Cells were finally incubated with rabbit polyclonal anti-Hsp70 (Calbiochem) and mouse monoclonal anti-microtubule associated protein (MAP)-2 (Sigma-Aldrich)-primary antibodies. The secondary antibodies were anti-rabbit-, or anti-mouse-IgGs, conjugated to rodhamine or to fluorescein (Promega Corporation). Nuclei were counterstained for DNA by treating with Vectashield mounting medium for fluorescence, containing 4'-,6-diamino-2phenylindole (DAPI; Vector Laboratories, Youngstown, $\mathrm{OH}$, USA) and observed in an Olympus BX-50 microscope (Olympus Italia s.r.1., Segrate, Italy) equipped with Vario Cam B/W camera (Nikon Instruments s.p.a., Calenzano, Italy).

\section{Results}

Effect of cadmium on brain cell vitality and morphology. As shown by the vitality assays (Figs. 1 and 2A), based on the ability of ethidium bromide to enter dead cells (that appear orange-red), all the analyzed brain cell types are sensitive to cadmium, especially those that divide more rapidly, such as the RBE4.B brain capillary endothelial cell line (Fig. 1d-f) and undifferentiated PC12 cells (Fig. 1g-i). Astrocytes tend to maintain their general morphology even at high doses of cadmium $(20 \mu \mathrm{M})$ (Fig. 1b). At the highest metal concentration $(50 \mu \mathrm{M})$, however, also astrocytes show alterations of the cell bodies and tend to detach from the fibronectin extracellular matrix (Fig. 1c). Neurons (Fig. 2A, a*-d*), as well as differentiated PC12 cells (Fig. 2A, a-d, and a'-d'), show a dramatic reduction of neurites, even at the lowest doses of the metal $(1 \mu \mathrm{M})$.

These morphological changes depend on the alteration of the cytoskeletal architecture. As shown in Fig. 2B, indeed, both the network of microtubules in neurons (a-e), and the network of intermediate filaments in astrocytes $\left(\mathrm{a}^{*}-\mathrm{e}^{*}\right)$ are dramatically affected by cadmium treatment, as indicated by the altered distribution of the microtubule associated protein 2 (MAP-2, a-e), and of the astrocyte-specific glial fibrillary acidic protein (GFAP, $\mathrm{a}^{*}-\mathrm{e}^{*}$ ), respectively. In the case of neurons, for example, MAP-2, and probably microtubules themselves, collapsed onto the nuclei, even at $1 \mu \mathrm{M}$ cadmium (Fig. 2B, b). In the case of astrocytes, higher doses of cadmium $(50 \mu \mathrm{M})$ are required in order to observe severe disassembly of the intermediate filaments and loss of the 

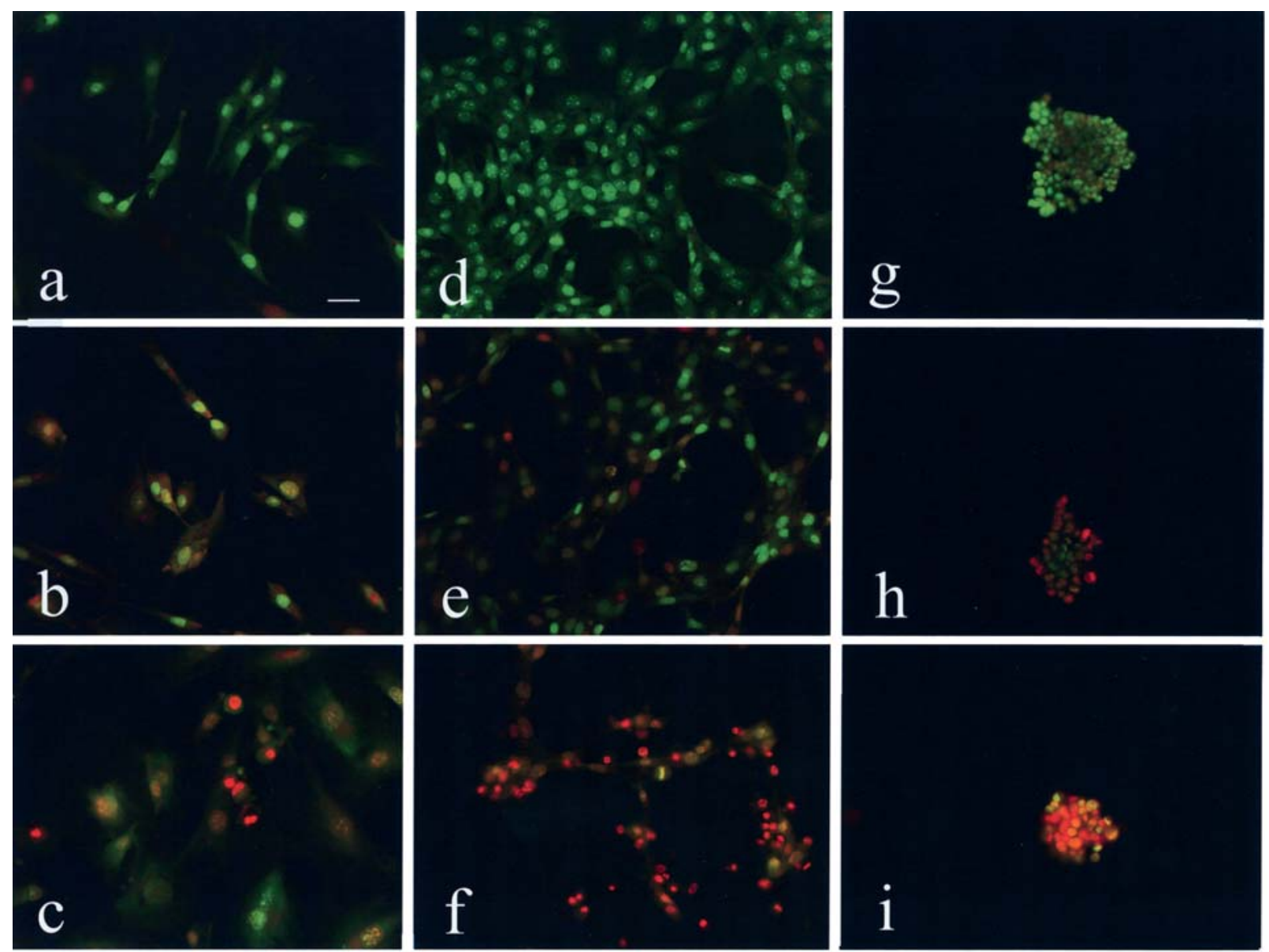

Figure 1. Control- and cadmium-treated cells stained with a combination of the fluorescent DNA-binding dyes acridine orange and ethidium bromide, $100 \mu \mathrm{g}$ each $/ \mathrm{ml}$ in PBS. Astrocytes (a-c) were treated with 0 (a), 20 (b) and 50 (c) $\mu \mathrm{M}$ cadmium. RBE4.B endothelial cells (d-f) were treated with 0 (d), 20 (e) and 50 (f) $\mu \mathrm{M}$ cadmium. Undifferentiated pheochomocytoma cells 12 (PC12) (g-i) were treated with 0 (g), 20 (h) and 50 (i) $\mu \mathrm{M}$ cadmium. Cell cultures were prepared as described in the text and treated with cadmium for $24 \mathrm{~h}$. Control cells were cultured for $24 \mathrm{~h}$ in the absence of the metal. Bar, $20 \mu$.

peculiar morphology of these cells. Differentiated PC12 cells (dPC12, Fig. 2B, a'-e') have on average less MAP-2 and higher amounts of Hsp70 than neurons and the effect of cadmium seems less dramatic, in comparison with the other cell types; however, the effect on cell branching is quite evident (Fig. 2A, a-d, and a'-d'; 2B, a'-e').

A relative increase of $\mathrm{Hsp} 70$ (green fluorescence) that accompanies disassembly of the cytoskeleton is also evident for all cell types, as shown in Fig. 2B.

Effect of cadmium on the expression of different chaperones. We studied the expression of three cell chaperones, the housekeeping Hsc70 and Hsp90, as well as the stress protein Hsp70. The Hsp70 levels increased in all cell types in response to cadmium treatment (Figs. 3-6), thus demonstrating that, as in other cell types, the metal induces a stress response both in primary brain cells, i.e. astrocytes (Fig. 3) and neurons (Fig. 4), and in brain cell-like cell lines, such as RBE4.B brain capillary endothelial cells (Fig. 5) and PC12 cells (Fig. 6). In the case of primary cortical neurons, however, the increase in the total amount of Hsp70 was highly variable among various neuronal cultures (Fig. 4, statistical analysis). Cadmium did not induce any significant alteration in the expression levels of the other two chaperones analyzed (Hsc70 and Hsp90) in PC12 cells (not shown), or in astrocytes (Fig. 3). On the other hand, a significant increase of both Hsc70 and Hsp90 was evident in the case of the brain capillary endothelial cell line (Fig. 5). Curiously, we noted the opposite tendency in neurons, where the concentration of both proteins decreased at the highest doses of cadmium (Fig. 4).

Effect of cadmium on the expression of PIPPin in cortical neurons. Finally, we investigated the effect of cadmium on the expression of PIPPin (also called CSD-C2), a putative RNA-binding protein discovered years ago in our laboratory (30). This protein contains a cold shock domain (31), and can probably bind both specific mRNAs and chromatin $(31,33)$. Because of its properties, PIPPin could be involved in translating environmental signals into post-transcriptional as well as transcriptional modification of the expression of genes relevant to cell response to stress. As shown in Fig. 7, PIPPin undergoes a clear decrease when neurons are treated with $50 \mu \mathrm{M}$ cadmium.

\section{Discussion}

Our results show that cadmium exposure induces severe damage in primary cultures of both cortical neurons and glial cells, as demonstrated by vitality assays. Similar to primary brain cells, two different cell lines, that we used as model of 

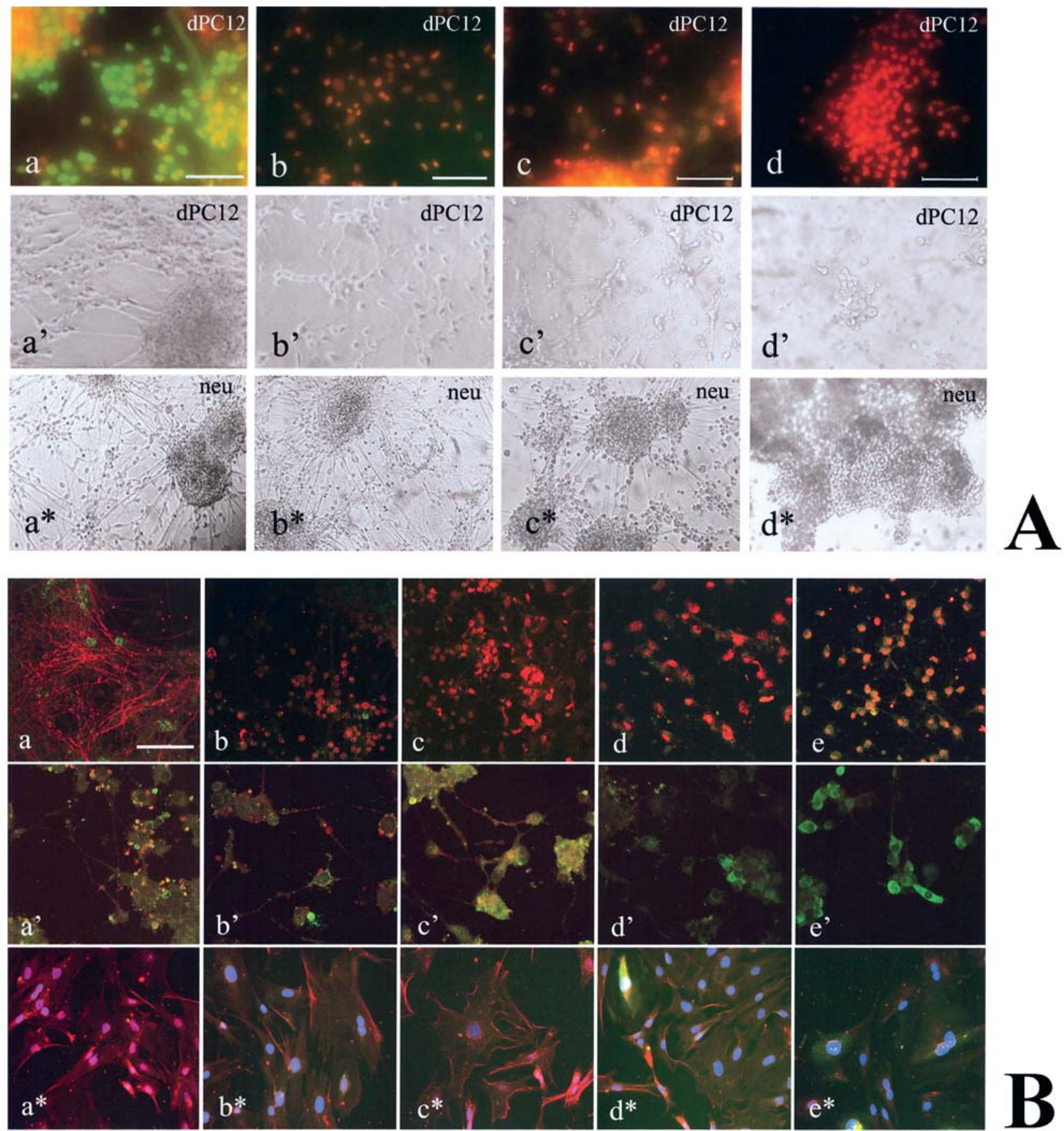

Figure 2. Effect of cadmium on NGF-differentiated PC12 cells (dPC12) and neurons (neu) (A). Cells were cultured as described in the text and treated with $0-\left(\mathrm{a}, \mathrm{a}^{\prime}\right.$, and $\left.\mathrm{a}^{*}\right), 1-\left(\mathrm{b}, \mathrm{b}^{\prime}\right.$, and $\left.\mathrm{b}^{*}\right), 5-\left(\mathrm{c}, \mathrm{c}^{\prime}\right.$, and $\left.\mathrm{c}^{*}\right)$, and 50- (d, $\mathrm{d}^{\prime}$ and $\left.\mathrm{d}^{*}\right) \mu \mathrm{M}$ cadmium, for $24 \mathrm{~h}$. Control- and cadmium-treated cells were stained with a combination of the fluorescent DNA-binding dyes acridine orange and ethidium bromide, $100 \mu \mathrm{g}$ each/ml in PBS (dPC12: a-d), and observed by fluorescent microscopy. Alternatively, cells were only observed by light microscope (dPC12: a'-d'; neurons: $\mathrm{a}^{*}-\mathrm{d}^{*}$ ). (B), effect of cadmium on the expression and localization of Hsp70 (green fluorescence) and cell-specific cytoskeletal proteins (red fluorescence) in neurons (a-e), NGF-differentiated PC12 cells (a'-e'), and astrocytes $\left(\mathrm{a}^{*}-\mathrm{e}^{*}\right)$. The red-stained, cell-specific protein is microtubule-associated protein 2 (MAP-2), in the cases of neurons and dPC12 cells, while it is glial fibrillary acidic protein (GFAP), in the case of astrocytes. Cell cultures were prepared as described in the text and treated with $0-\left(a, a^{\prime}, a^{*}\right), 1-\left(b, b^{\prime}, b^{*}\right)$, 5- $\left(\mathrm{c}, \mathrm{c}^{\prime}, \mathrm{c}^{*}\right), 20-\left(\mathrm{d}, \mathrm{d}^{\prime}, \mathrm{d}^{*}\right)$ or 50- $\mu \mathrm{M}$ cadmium, for $24 \mathrm{~h}$. In addition, all cells were also stained with DAPI. The image shows the overlay of the three fluorescences. Cells were observed in an Olympus BX-50 microscope, equipped with Vario Cam B/W camera. Bar, $50 \mu$.

either neurons (i.e. pheochromocytoma cells, induced to differentiate into neurons by NGF treatment), or brain capillary endothelial cells (i.e. RBE4.B cells) were also damaged by cadmium.

A target of these damaging effects is the cytoskeleton, especially in neurons and neuronal-like NGF-treated PC12 cells, where the metal always induces a dramatic disassembly of neurites and the complete disappearance of microtubules, which seem to collapse onto the nuclear surface.

On the other hand, we found that the responses to the metal are cell-specific when it concerns the expression of Hsc70 and Hsp90, in astrocytes, as well as in PC12 cells, indeed, cadmium had no significant effect, whereas, in endothelial cells, an increase of both proteins is clearly 


\section{$\begin{array}{lllll}C & 1 & 5 & 20 & 50\end{array}$}

a

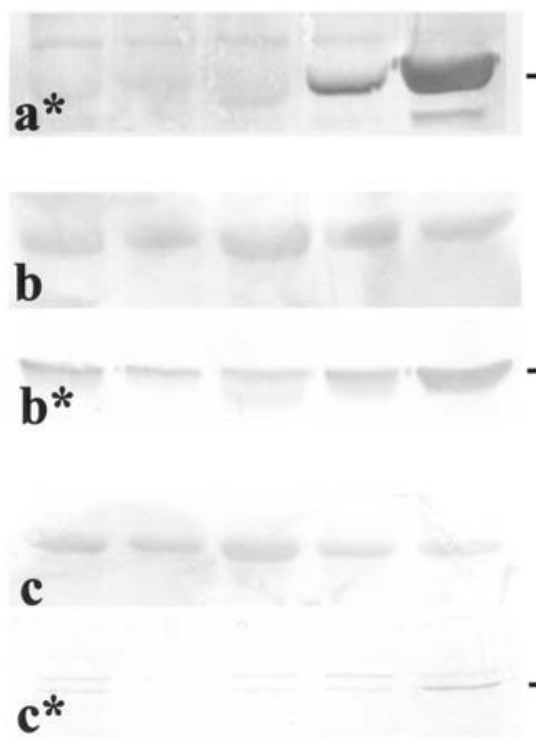

$-\mathrm{Hsp} 70$

$-\mathrm{Hsc} 70$

-Hsp90
$\begin{array}{lllll}C & 1 & 5 & 20 & 50\end{array}$
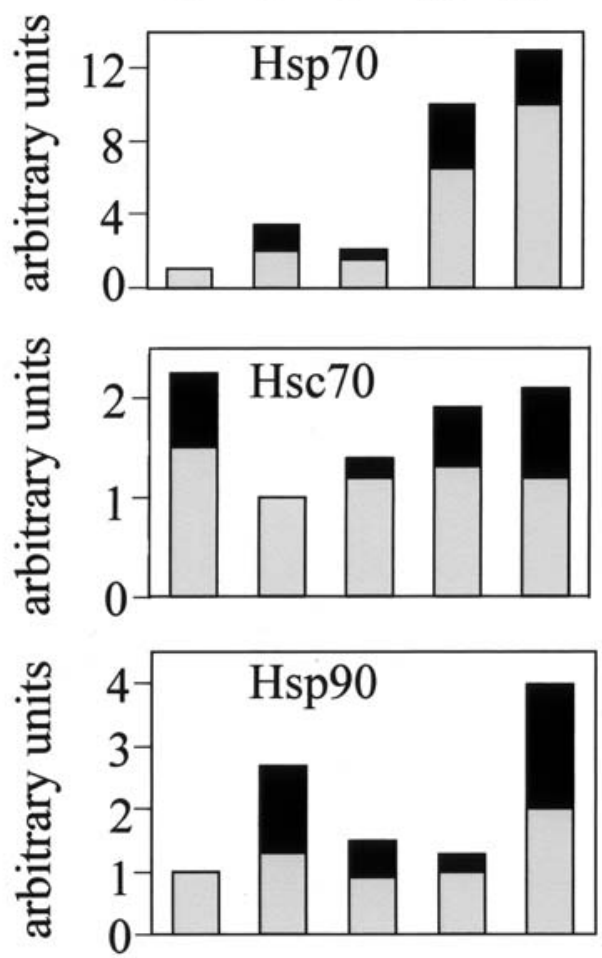

Figure 3. Western blot analysis of total cell proteins from astrocytes, purified and cultured as described in the text and treated with $0,1,5,20$, or $50 \mu \mathrm{M}$ cadmium, for $24 \mathrm{~h}$. Total proteins from cell lysates were immunostained with rabbit polyclonal anti-Hsp70 antibodies ( $\left.\mathrm{a}^{*}\right)$, or mouse polyclonal anti-Hsc70 antibodies $\left(b^{*}\right)$, or mouse monoclonal anti-Hsp90 antibodies $\left(c^{*}\right)$. Ponceau red-stained regions of the same membranes used for the Western blot analyses reported in $\mathrm{a}^{*}, \mathrm{~b}^{*}$ and $\mathrm{c}^{*}$ are shown in $\mathrm{a}, \mathrm{b}$, and c, respectively. At least three independent Western blots were scanned and analyzed with the ImageJ program. The results were used to calculate mean relative concentrations of the proteins of interest (on the right). Grey bars indicate mean values. Black bars represent standard deviations (SD).

\section{C $\quad 1 \quad 5 \quad 2050$}

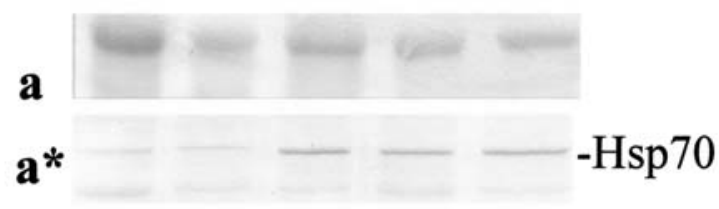

b

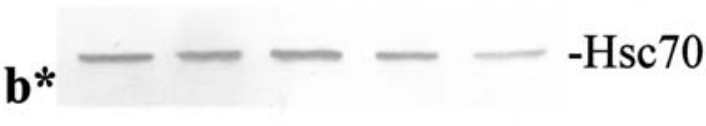

c

$\mathbf{c}^{*}$
C $\quad 1 \quad 52050$
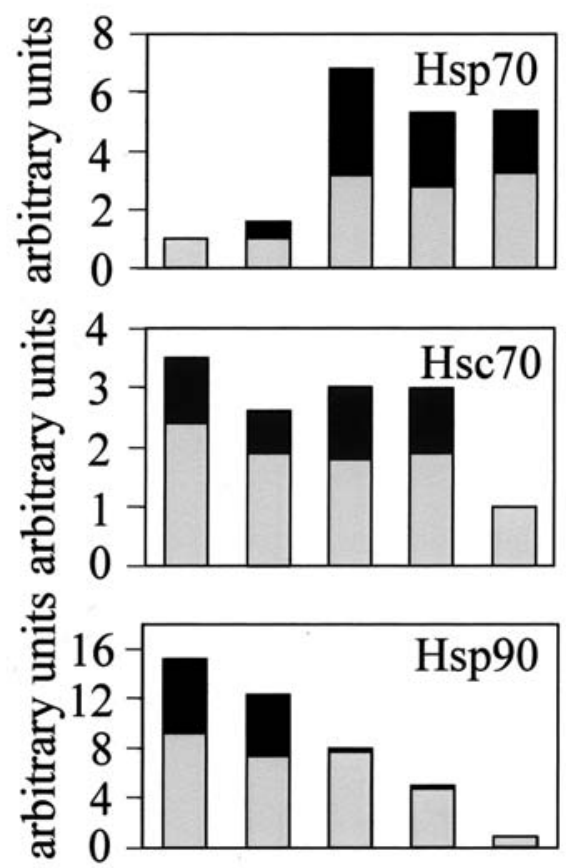

Figure 4. Western blot analysis of total cell proteins from neurons, purified and cultured as described in the text and treated with $0,1,5,20$, or $50 \mu \mathrm{M}$ cadmium, for $24 \mathrm{~h}$. Total proteins from cell lysates were immunostained with rabbit polyclonal anti-Hsp70 antibodies ( $\mathrm{a}^{*}$ ), or mouse polyclonal anti-Hsc70 antibodies $\left(b^{*}\right)$, or mouse monoclonal anti-Hsp90 antibodies $\left(c^{*}\right)$. Ponceau red-stained regions of the same membranes used for the Western blot analyses reported in $\mathrm{a}^{*}, \mathrm{~b}^{*}$ and $\mathrm{c}^{*}$ are shown in $\mathrm{a}, \mathrm{b}$, and c, respectively. At least three independent Western blots were scanned and analyzed with the ImageJ program. The results were used to calculate mean relative concentrations of the proteins of interest (on the right). Grey and black bars indicate mean values and SD, respectively. 


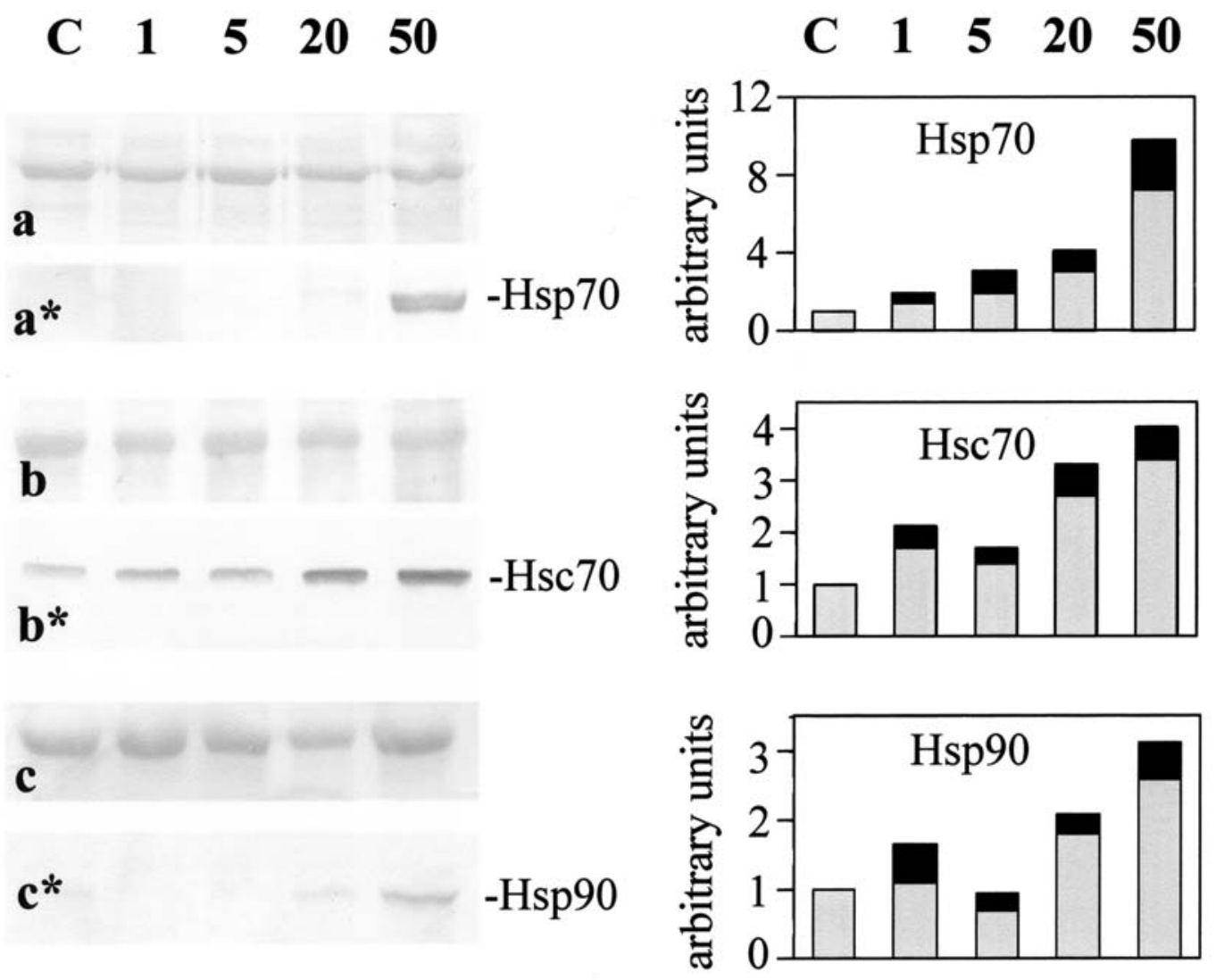

Figure 5. Western blot analysis of total cell proteins from RBE4.B endothelial cells, cultured as described in the text and treated with $0,1,5,20$, or $50 \mu \mathrm{M}$ cadmium, for $24 \mathrm{~h}$. Total proteins from cell lysates were immunostained with rabbit polyclonal anti-Hsp70 antibodies ( $\left.\mathrm{a}^{*}\right)$, or mouse polyclonal anti-Hsc70 antibodies $\left(b^{*}\right)$, or mouse monoclonal anti-Hsp90 antibodies $\left(c^{*}\right)$. Ponceau red-stained regions of the same membranes used for the Western blot analyses reported in $\mathrm{a}^{*}, \mathrm{~b}^{*}$ and $\mathrm{c}^{*}$ are shown in $\mathrm{a}, \mathrm{b}$, and c, respectively. At least three independent Western blots were scanned and analyzed with the ImageJ program. The results were used to calculate mean relative concentrations of the proteins of interest (on the right). Grey bars indicate mean values. Black bars represent standard deviations (SD).

\section{C $\quad 1 \quad 5 \quad 20 \quad 50$}
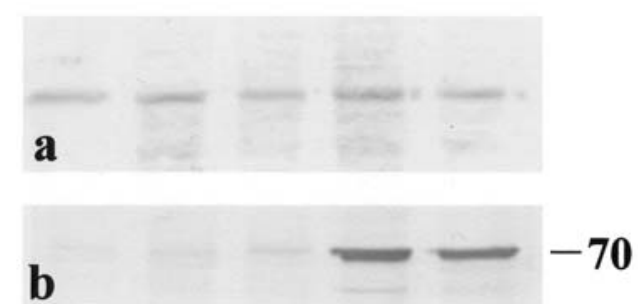

\section{$\begin{array}{lllll}C & 1 & 5 & 20 & 50\end{array}$}
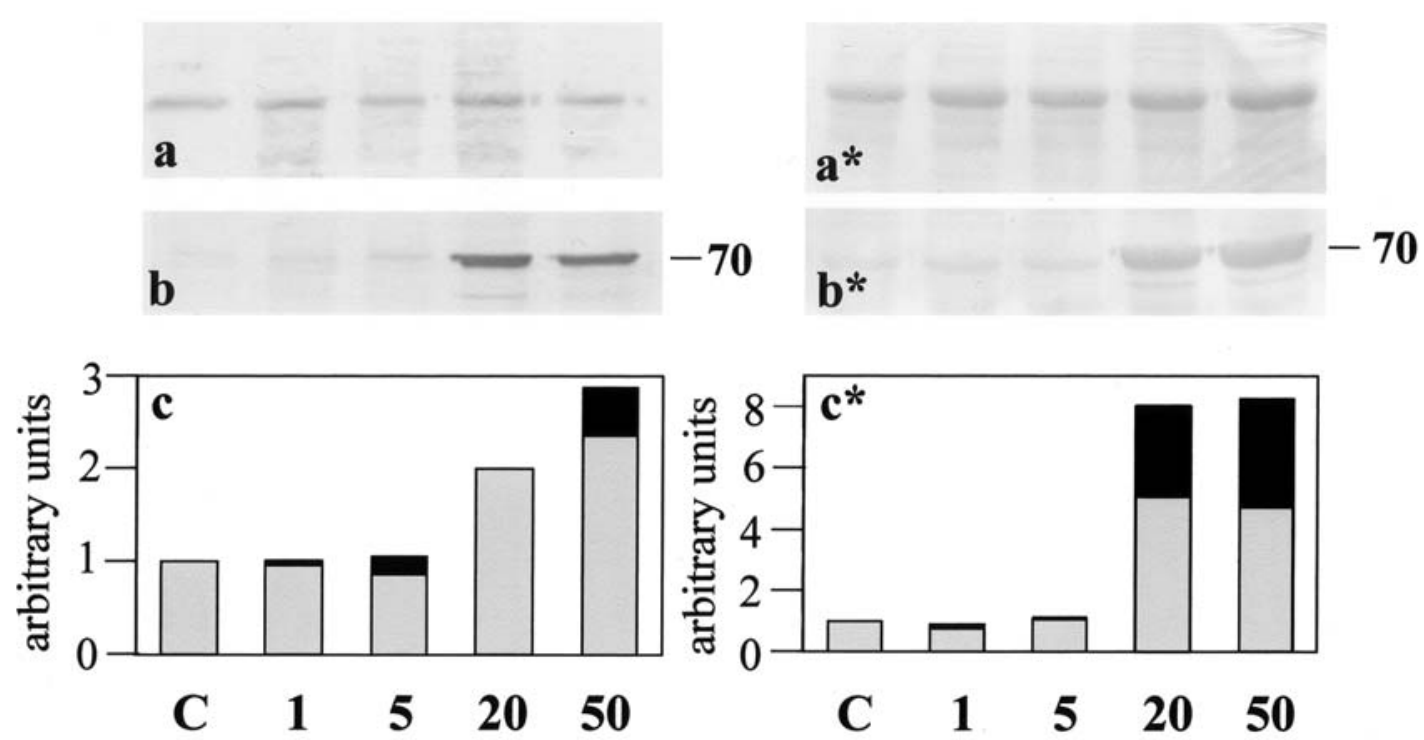

Figure 6. Western blot analysis of total cell proteins from undifferentiated PC12 cells (a-c) and from PC12 cells induced to differentiate by NGF ( $\mathrm{a}^{*}-\mathrm{c}^{*}$ ), cultured as described in the text and treated with $0,1,5,20$, or $50 \mu \mathrm{M}$ cadmium, for $24 \mathrm{~h}$. Total proteins from cell lysates were immunostained with rabbit polyclonal anti-Hsp70 antibodies $\left(b\right.$, and $\left.b^{*}\right)$. Ponceau red-stained regions of the same membranes used for the Western blot analyses reported in $b$ and $b^{*}$ are shown in a and $a^{*}$, respectively. At least three independent Western blots were scanned and analyzed with the ImageJ program. The results were used to calculate mean relative concentrations of Hsp70 (lower part of the image). Grey and black bars represent mean values and standard deviations, respectively. 


\section{$\begin{array}{lllll}C & 1 & 5 & 20 & 50\end{array}$}

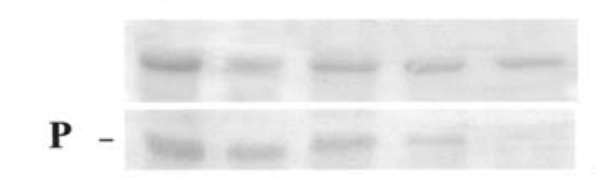

A

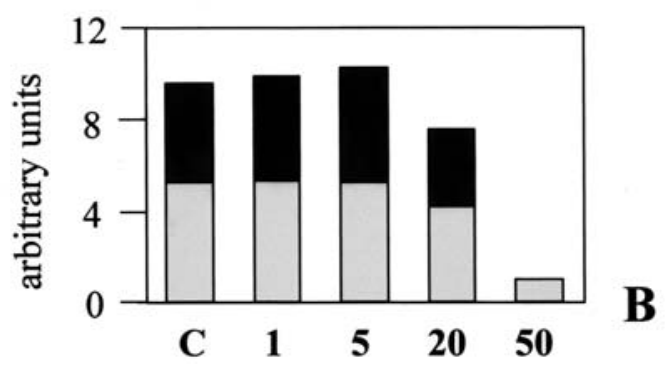

Figure 7. Western blot analysis of total cell proteins from neurons, cultured as described in the text and treated with $0,1,5,20$, or $50 \mu \mathrm{M}$ cadmium, for $24 \mathrm{~h}$. (A) total proteins from cell lysates were immunostained with rabbit polyclonal anti-PIPPin $(\mathrm{P})$ antibodies produced in our laboratory (lower row). A representative Ponceau red-stained region of the same membrane used for the Western blot analysis is shown in the upper row. (B) Ten independent Western blots were scanned and analyzed with the ImageJ program. The results were used to calculate mean relative concentrations of PIPPin. Grey and black bars represent mean values and standard deviations, respectively.

observable after treatment with at least $20 \mu \mathrm{M}$ cadmium. In the case of neurons, we observed that both Hsp90 and Hsc70 decrease after exposure to $20 \mu \mathrm{M}$ cadmium.

As expected, the metal induces a dose-dependent increase of Hsp70 (the classical stress protein in the family), in all cell types, although in neurons this response shows a high degree of variability.

Finally, we analyzed the possible effects of cadmium exposure on the expression in neurons of proteins not directly linked to stress. In particular, we studied the effects of the metal on PIPPin (also known as CSD-C2), a putative RNAbinding protein, highly expressed in neurons and probably involved in the regulation of histone replacement variant expression. Herein we report that high doses of cadmium $(50 \mu \mathrm{M})$ induce a clear decrease of this protein. Although an interpretation of this observation deserves a full understanding of the actual PIPPin functions in the cells, we already know that this protein can exist in phosphorylated $(31,34)$, as well as sumoylated forms (33). Moreover, its post-translational modifications have been related to specific extracellular stimuli at least in some cases (33). On the other hand, PIPPin is most closely related to CRHSP24, a protein particularly abundant in pancreas, testis, liver, and lung. CRHSP24 has been suggested to be involved in calcium-mediated signal transduction (39). As cadmium has been reported to interfere with calcium homeostasis in nerve cells (23-25), we suggest that PIPPin might be a novel and central target of cadmium action in the brain.

\section{Acknowledgements}

We wish to thank Mr. S. Agnello for helpful assistance with confocal microscopy. This work was supported by the
University of Palermo (fondi di Ateneo, Università degli Studi di Palermo). C. Gerspacher and U. Scheuber were supported by an Erasmus exchange program between the University of Applied Sciences of Northwestern Switzerland, Muttenz, and the University of Palermo (Italy), P. Proia was supported by $\mathrm{Ph} . \mathrm{D}$ fellowship of the Università degli Studi di Palermo, Palermo, Italy. G. Schiera was supported by a postdoctoral fellowship by Università degli Studi di Palermo, Palermo, Italy.

\section{References}

1. ATSDR, 2005, http://www.atsdr.cdc.gov.clist.html

2. Klaassen CD and Liu J: Role of metallothionein in cadmiuminduced hepatotoxicity and nephrotoxicity. Drug Metab Rev 29: 79-102, 1997.

3. Xu C, Johnson JE, Singh PK, Jones MM, Yan H and Carter CE: In vivo studies of cadmium-induced apoptosis in testicular tissue of the rat and its modulation by a chelating agent. Toxicology 107: 1-8, 1996.

4. Habeebu SS, Liu J and Klaassen CD: Cadmium-induced apoptosis in mouse liver. Toxicol Appl Pharmacol 149: 203-209, 1998.

5. Tsangaris GT and Tzortzatou-Stathopoulou F: Cadmium induces apoptosis differentially on immune system cell lines. Toxicology 128: 143-150, 1998.

6. Au DW, Reunov AA and Wu RS: Reproductive impairment of sea urchin upon chronic exposure to cadmium. Part II: Effects on sperm development. Environ Pollut 111: 11-20, 2001.

7. Fernandez $\mathrm{N}$ and Beiras R: Combined toxicity of dissolved mercury with copper, lead and cadmium on embryogenesis and early larval growth of the Paracentrotus lividus sea-urchin. Ecotoxicology 10: 263-271, 2001.

8. Chow ESH, Hui MNY, Lin CC and Cheng SH: Cadmium inhibits neurogenesis in zebrafish embryonic brain development. Aquat Toxicol 87: 157-169, 2008.

9. Agnello M, Filosto S, Scudiero R, Rinaldi AM and Roccheri MC: Cadmium induces an apoptotic response in sea urchin embryos. Cell Stress Chaperones 12: 44-50, 2007.

10. Roccheri MC, Agnello M, Bonaventura R and Matranga V: Cadmium induces the expression of specific stress proteins in sea urchin embryos. Biochem Biophys Res Commun 321: 80-87, 2004.

11. Stohs SJ and Bagchi D: Oxidative mechanisms in the toxicity of metal ions. Free Radic Biol Med 18: 321-336, 1995.

12. Figueiredo-Pereira ME, Li Z, Jansen M and Rockwell P: NAcethylcysteine and colecoxib lessen cadmium cytotoxicity which is associated with cyclooxygenase-2 up-regulation in mouse neuronal cells. J Biol Chem 277: 25283-25289, 2002.

13. Wang Y, Fang J, Leonard SS, Krishna K and Rao M: Cadmium inhibits the electron transfer chain and induces reactive oxygen species. Free Radic Biol Med 36: 1434-1443, 2004.

14. Monroe RK and Halvorsen SW: Cadmium blocks receptormediated Jak/STAT signalling in neurons by oxidative stress. Free Radic Biol Med 41: 493-502, 2006.

15. López E, Arce C, Oset-Gasque MJ, Cañadas S and Gonzáles MP: Cadmium induces reactive oxygen species generation and lipid peroxidation in cortical neurons in culture. Free Radic Biol Med 40: 940-951, 2006.

16. Nollen EA and Morimoto RI: Chaperoning signalling pathways: molecular chaperones as stress-sensing 'heat shock' proteins. J Cell Sci 115: 2809-2816, 2002.

17. Geraci F, Turturici G, Galli D, Cossu G, Giudice G and Sconzo G: Stress response in mesoangioblast stem cells. Cell Death Diff 13: 1057-1063, 2006.

18. Evans $\mathrm{J}$ and Hastings L: Accumulation of $\mathrm{Cd}(\mathrm{II})$ in the CNS depending on the route of administration: intraperitoneal, intratracheal, or intranasal. Fundam Appl Toxicol 19: 275-278, 1992.

19. Shukla A, Shukla GS and Srimal RC: Cadmium-induced alterations in blood-brain barrier permeability and its possible correlation with decreased microvessel antioxidant potential in rat. Hum Exp Toxicol 15: 400-405, 1996.

20. Jeong EM, Moon CH, Kim CS, Lee SH, Baik EJ, Moon CK and Jung YS: Cadmium stimulates the expression of ICAM-1 via NF-kappaB activation in cerebrovascular endothelial cells. Biochem Biophys Res Commun 320: 887-892, 2004. 
21. Seok SM, Park DH, Kim Y-C, Moon C-H, Jung Y-S, Baik EJ, Moon C-K and Lee SH: COX-2 is associated with cadmiuminduced ICAM-1 expression in cerebrovascular endothelial cells. Toxicol Lett 165: 212-220, 2006.

22. Bertin G and Averbeck D: Cadmium: cellular effects, modifications of biomolecules, modulation of DNA repair and genotoxic consequences (a review). Biochimie 88: 1549-1559, 2006.

23. Yamagami K, Nishimura $\mathrm{M}$ and Sorimachi $\mathrm{M}: \mathrm{Cd}^{2+}$ and $\mathrm{Co}^{2+}$ at micromolar concentrations stimulate catecholamine secretion by increasing the cytosolic free $\mathrm{Ca}^{2+}$ concentration in cat adrenal chromaffin cells. Brain Res 646: 295-298, 1998.

24. Molnar G, Salanki J and Kiss T: Cadmium inhibits GABAactivated ion currents by increasing intracellular calcium level in snail neurons. Brain Res 1008: 205-211, 2004.

25. Nishimura Y, Yamaguchi J-Y, Kanada A, Horimoto K, Kanemaru K, Satoh M and Oyama Y: Increase in intracellular $\mathrm{Cd}^{2+}$ concentration of rat cerebellar granule neurons incubated with cadmium chloride: cadmium cytotoxicity under external $\mathrm{Ca}^{2+}$-free condition. Toxicol In Vitro 20: 211-216, 2006.

26. Antonio MT, Benito MJ, Leret ML and Corpas I: Gestational administration of cadmium alters the neurotransmitter levels in newborn rat brains. J Appl Toxicol 18: 83-88, 1998.

27. Minami A, Takeda A, Nishibaba D, Takefuta S and Oka N: Cadmium toxicity in synaptic neurotransmission in the brain. Brain Res 894: 336-339, 2001.

28. Liu Y-P, Yang C-S and Tzeng S-F: Inhibitory regulation of glutamate aspartate transporter (GLAST) expression in astrocytes by cadmium-induced calcium influx. J Neurochem 105: 137-150, 2008

29. Wang S, Hu P, Wang H-L, Wang M, Chen J-T, Tang J-L and Ruan D-Y: Effects of Cd on AMPA receptor-mediated synaptic transmission in rat hippocampal CA1 area. Toxicol Lett 176: 215-222, 2008

30. Castiglia D, Scaturro M, Nastasi T, Cestelli A and Di Liegro I: PIPPin, a putative RNA-binding protein specifically expressed in the rat brain. Biochem Biophys Res Commun 218: 390-394, 1996.
31. Nastasi T, Scaturro M, Bellafiore M, Raimondi L, Beccari S, Castelli A and Di Liegro I: PIPPin is a brain-specific protein that contains a cold-shock domain and binds specifically to $\mathrm{H} 1^{\circ}$ and H3.3 mRNAs. J Biol Chem 274: 24087-24093, 1999.

32. Nastasi T, Muzi P, Beccari S, Dolo V, Bologna M, Cestelli A and Di Liegro I: Specific neurons of brain cortex and cerebellum are PIPPin-positive. Neuroreport 11: 2233-2236, 2000.

33. Bono E, Compagno V, Proia P, Raimondi L, Schiera G, Favaloro V, Campo V, Donatelli M and Di Liegro I: Thyroid hormones induce sumoylation of the cold shock domaincontaining protein PIPPin in developing rat brain and in cultured neurons. Endocrinology 148: 252-257, 2007.

34. Auld G, Campbell DG, Morrice N and Cohen P: Identification of calcium-regulated heat-stable protein of $24 \mathrm{kDa}$ (CRHSP24) as a physiological substrate for PKB and RSK using KESTREL. Biochem J 389: 775-783, 2005.

35. Savettieri G, Licata L, Catania C, Raneri R, DiLiegro I and Cestelli A: Synergistic effects of laminin and thyroid hormones on neuron polarity in culture. Neuroreport 10: 1269-1272, 1999.

36. Proia P, Schiera G, Mineo M, Ingrassia AMR, Santoro G, Savettieri G and Di Liegro I: Astrocytes shed extracellular vesicles that contain fibroblast growth factor-2 and vascular endothelial growth factor. Int J Mol Med 21: 63-67, 2008.

37. Roux F, Durieu-Trautmann O, Chaverot N, Claire M, Mailly P, Bourre JM, Strosberg AD and Courad PO: Regulation of gammaglutamyl transpeptidase and alkaline phosphatase activities in immortalized rat brain microvessel endothelial cells. J Cell Physiol 159: 101-113, 1994.

38. Schiera G, Proia P, Alberti C, Mineo M, Savettieri G and Di Liegro I: Neurons produce FGF2 and VEGF and secrete them at least in part by shedding extracellular vesicles. J Cell Mol Med 11: 1384-1394, 2007.

39. Groblewski GE, Yoshida M, Bragado MJ, Ernst SA, Leykan J and Williams JA: Purification and characterization of a novel physiological substrate for calcineurin in mammalian cells. J Biol Chem 273: 22738-22744, 1998. 